\title{
Notas sobre o feminismo e gênero: compreendendo a relação das categorias com as políticas públicas no Brasil
} Notes on feminism and gender: understanding the relationship
of the categories with public policies in Brazil

\author{
Bianca Gonçalves Santos Lima* \\ Maria Helena Santana Cruz**
}

\begin{abstract}
Resumo - O presente artigo discorre sobre o feminismo, sua trajetória como movimento social fundamental na busca dos direitos das muIheres e de que maneira se desenvolveu no Brasil. Foram destacados os estudos feministas e os estudos de gênero para entender os temas que eram fortemente discutidos no interior do movimento e que davam direcionamento para o debate sobre as pautas necessárias. Além disso, discorre-se também sobre a compreensão do termo gênero e a importância dessa categoria, relacionando-a com as políticas públicas brasileiras. A pesquisa, fundamentada no método materialista históricodialético, possui cunho teórico que utiliza a abordagem qualitativa e o levantamento bibliográfico, buscando compreender e investigar o objeto escolhido por meio do mapeamento de produções acadêmicas publicadas no catálogo de teses e dissertações da Capes relacionadas à temática.
\end{abstract}

Palavras-chave: feminismo; gênero; políticas públicas; estudos feministas; estudos de gênero.

\begin{abstract}
This article discusses feminism, its trajectory as a fundamental social movement in the fight for women's rights, and how it developed in Brazil. Feminist studies and gender studies were highlighted to understand the themes that were strongly discussed in the movement and gave direction to debates on the agenda. In addition, it also discusses the understanding of the term gender and the importance of this category, relating it to Brazilian public policies. The research, based on the historical-dialectical materialist method, has a theoretical nature, using a qualitative approach and a bibliographic survey, in which it seeks to understand and investigate the chosen object through the mapping of academic productions related to the theme published in the Theses and Dissertations Catalog of CAPES.
\end{abstract}

Keywords: feminism; gender; public policy; feminist studies; gender studies.

\footnotetext{
* Mestranda em Serviço Social no Programa de Pós-graduação em Serviço Social (PROSS) pela Universidade Federal de Sergipe (UFS). E-mail: biancalima12@gmail.com. ORCID: https://orcid.org/0000-0002-1513-3434.

** Pós-doutorado em Sociologia da Educação, Doutora e Mestra em Educação (UFBA). Professora Emérita da Universidade Federal de Sergipe (UFS). E-mail: helenacruz@uol.com.br. ORCID: https://orcid.org/0000-0002-7794-278X.
} 
\} NOTAS SOBRE O FEMINISMO - LIMA, B. G. S.; CRUZ, M. H. S. \}

DOI: $10.12957 /$ rep.2021.56077

\section{Introdução}

O feminismo foi, e continua sendo, um movimento fundamental na luta das mulheres para serem reconhecidas e respeitadas como sujeitos de direitos em uma sociedade marcada fortemente pelas diversas formas de discriminação e opressão. Refletir sobre o movimento feminista é necessário para a compreensão dos desafios enfrentados pelas mulheres, cujo objetivo é a reivindicação de seus direitos, em busca de equidade e igualdade. Tendo isso em vista, o presente artigo pretender analisar, inicialmente, algumas considerações acerca da categoria feminismo, mais precisamente como esse movimento surgiu e se fortaleceu no Brasil.

As pautas discutidas no movimento feminista são de fundamental importância para o enfrentamento dos desafios estruturais a que as mulheres estão submetidas. Os estudos feministas tiveram um papel significativo nos debates promovidos pelo movimento, porém, não abrangiam de maneira eficiente as discussões realizadas. Dessa forma, são introduzidos os estudos de gênero, os quais possibilitaram a compreensão das relações sociais e as relações de poder que estão inerentes à sociedade.

Além disso, é trazida neste artigo uma discussão sobre a relevância das categorias "feminismo" e "gênero" articuladas ao desenvolvimento das políticas públicas. A discussão de gênero foi um marco na conquista pela equidade e pela igualdade dentro das políticas públicas, através dos diálogos que ocorreram em encontros e congressos internacionais, resultando na criação de meios visando à garantia, ao respeito e à ampliação dos direitos das mulheres. Faz-se necessário destacar a notoriedade das mulheres inseridas no movimento e como elas contribuíram na elaboração de acordos, protocolos e convenções que são de fundamental importância até os dias atuais.

O feminismo é um movimento que busca transformar a sociedade e livrar as mulheres das relações de opressão e submissão que lhes são impostas e que foram historicamente construídas e naturalizadas pelo sistema patriarcal. É relevante estudar as produções teóricas publicadas acerca desse tema para compreender o processo histórico da construção da estrutura social para que, assim, sejam criadas formas concretas de romper com os obstáculos da ordem vigente e garantir a emancipação das mulheres.

É importante destacar como o movimento feminista ocupou os diferentes espaços políticos e como ele influencia ao redor do mundo, em uma posição de conflito com as relações de poder e as demais adversidades. Mesmo com todo o histórico, evolução e mobilização, as mulheres ainda não alcançaram todas as reivindicações para sua total libertação, por isso, faz-se necessário refletir sobre a importância das políticas públicas relacionadas ao movimento feminista e destacar a importância de ouvir a voz das mulheres na busca de eliminar toda e qualquer forma de discriminação. 
Para a realização dessa pesquisa, foi utilizado o método materialista histórico-dialético, buscando compreender a temática a partir da perspectiva de totalidade diante dos determinantes sociais que a abrangem. A investigação se caracteriza por ter caráter teórico, feita a partir da aproximação com leituras selecionadas no catálogo de teses e dissertações da Capes, em que se adota a abordagem qualitativa, bem como faz-se pesquisa bibliográfica de fontes relacionadas ao tema proposto.

O conteúdo do presente artigo se organiza a partir de quatro seções, juntamente com esta introdução e as considerações finais. O primeiro tópico refere-se a uma breve abordagem relacionada ao feminismo e como o movimento se instituiu no Brasil. Já no segundo, é trazida a importância da inserção dos estudos de gênero somados aos estudos feministas no movimento. Em seguida, faz-se fundamental trazer a importância em abordar a categoria gênero e como esta marcou um avanço nas discussões. Por último, são destacadas as políticas públicas e como elas ocorreram no decorrer dos anos.

\section{Breves considerações acerca do feminismo e sua história no Brasil}

O feminismo é um conceito de complexa definição, mas pode ser entendido como um movimento político-cultural de mulheres que lutam pela igualdade de direitos e pela libertação de valores associados ao patriarcado, visando ao empoderamento das mulheres diante de uma sociedade que é marcada fortemente pela existência de condições de desigualdade e opressão. Segundo Duarte (2003, p. 2), "[...] o 'feminismo' poderia ser compreendido em um sentido amplo, como todo gesto ou ação que resulte em protesto contra a opressão e a discriminação da mulher, ou que exija a ampliação de seus direitos civis e políticos, seja por iniciativa individual, seja de grupo".

Diante de uma sociedade marcada fortemente pela opressão em diferentes contextos, as mulheres buscam a resistência nas situações em que estão submetidas. A opressão existente na família, na política, no trabalho e nos demais espaços sociais pode também se expressar de maneira velada, quando os espaços de fala são negados e a representação feminina é quase inexistente. Para eliminar esses dilemas, as mulheres buscam transformar a sociedade ativamente através do movimento feminista (PIMENTEL, 2017).

O movimento tem avançado nas últimas quatro décadas e as pautas que envolvem as mulheres são discutidas para que suas reivindicações e demandas sejam garantidas e consideradas, as quais são definidas por fatores como tempo e espaço, social ou geográfico. A luta pelos interesses de gênero é constante, visto que vivemos em uma sociedade marcada por profundas desigualdades de gênero, combinadas com o sexismo, lesbofobia, racismo, 
entre outras formas de dominação e desigualdade (SARDENBERG; COSTA, 2012).

Trata-se mais de eliminar as desigualdades sociais entre homens e mulheres do que fazer com que as mulheres cheguem onde os homens já estão, ou seja, aquilo que eles são, porque é um erro pensar que a sociedade dos homens permanecerá igual quando a das mulheres mudar. (FERREIRA, 1988, p. 94).

Foi o movimento feminista que transformou determinadas condições sociais e possibilitou que as mulheres fossem consideradas como parte integrante da sociedade diante da desigualdade de gênero existente. Mulher ter direito de ser universitária, de escolher a profissão e de se candidatar nos cargos que queira são bandeiras que fazem parte do nosso cotidiano, mas antigamente não foi assim.

No senso comum, o termo "feminismo" muitas vezes é visto como uma ofensa, sendo considerado o contrário do que é "feminino". A discussão acerca da expressão ainda perdura em meio à sociedade, sendo entendido como um tabu. $\mathrm{O}$ antifeminismo foi se fortalecendo durante os anos e o movimento sofreu um forte preconceito por parte das próprias mulheres, que associaram a mulher feminista às mulheres com características opostas à "feminilidade".

No Brasil, a história do feminismo é dividida em quatro "momentos áureos", em que cada um deles trazia a discussão de pautas importantes à sua época. Vale mencionar cada um deles para compreender melhor a sua trajetória. O primeiro período, denominado "momento-onda", aconteceu no século XIX, quando as mulheres brasileiras reivindicaram o direito de saber ler e escrever. $\mathrm{O}$ alcance desse direito foi para poucas mulheres, mas as que conseguiram estar incluídas tiveram contato com a literatura, escreveram livros e abriram escolas. No ano de 1870, aconteceu o segundo momento, caracterizado pelo enorme quantitativo de jornais feministas ao redor do país. Além disso, as pautas abordadas estavam relacionadas às exigências a favor do voto, à educação superior, à profissionalização feminina e ao trabalho renumerado para as mulheres (DUARTE, 2003).

Duarte (2003) ainda aborda o terceiro momento, em que o movimento se encontrava ainda mais organizado. As mulheres traziam à tona pautas extremamente importantes; como afirma a autora (DUARTE, 2003, p. 10), elas reivindicavam "[...] o direito ao voto, ao curso superior e à ampliação do campo de trabalho, pois queriam não apenas ser professoras, mas também trabalhar no comércio, nas repartições, nos hospitais e indústrias". O quarto momento aconteceu nos anos 1970, período em que as feministas conseguiram transformar radicalmente determinados costumes. Foram organizados encontros e congressos onde eram debatidos temas relacionados à maior visibilidade da mulher, como a conscientização política, 


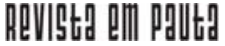

\} NOTAS SOBRE O FEMINISMO - LIMA, B. G. S.; CRUZ, M. H. S. \}

DOI: $10.12957 /$ rep.2021.56077

a melhoria nas condições de trabalho, o direito à legalização do aborto, o direito ao prazer e à sexualidade.

O feminismo contemporâneo surgiu na época da ditadura militar, quando a luta visava à redemocratização do país articulada à oposição à opressão das mulheres. Além disso, também discutiram novas pautas voltadas para a desigualdade de gênero, como a violência doméstica e o direito ao prazer, entre outras (SARDENBERG; COSTA, 2012).

Sardenberg e Costa (2012) ainda discorrem que, nos anos 1990, diferentes temáticas se fortalecem dentro do movimento. $\mathrm{O}$ fato de que algumas mulheres não estavam submetidas no mesmo nível, por consequência da diversidade cultural, étnica, racial e social, as colocava em uma posição diferente de subordinação, em que umas sofriam mais que as outras. Dessa forma, tais dimensões permitiram uma maior abertura e heterogeneidade no feminismo, para que as demandas de todas as mulheres tivessem a atenção necessária da sociedade e do Estado e fossem consideradas diante do contexto em que estavam inseridas. Esse processo de fragmentação deu abertura a novos tipos de feminismos.

Mulheres das classes trabalhadoras se articularam através de associações de bairro; trabalhadoras das fábricas, através de departamentos de mulheres de seus sindicatos e centrais nacionais; trabalhadoras rurais, através de suas várias organizações. Esses diferentes segmentos do movimento de mulheres começaram a identificar-se com propostas feministas, constituindo o chamado 'feminismo popular'. Além disso, organizações de mulheres negras continuaram a crescer e ampliar a agenda política feminista, redefinindo os parâmetros das próprias lutas feministas, a ponto de podermos falar da 'existência de vários feminismos - com pontos de vista, questões centrais, meios de organização e prioridades estratégicas feministas diversas - serem amplamente reconhecidos nos anos 1990'. (ALVAREZ apud SARDENBERG; COSTA, 2012, p.8).

O contexto sócio-histórico dos anos 1990 foi - e continua sendo - fortemente marcado pelo avanço da ideologia conservadora e do agravamento de preconceitos e discriminações. Esse cenário desfavorável influenciou diretamente na luta dos movimentos feministas, enfrentando ferrenhos desafios para garantir as conquistas já efetivadas e resistindo para que os novos direitos necessários sejam reconhecidos e garantidos (ROCHA, 2016).

Apesar dos avanços, o feminismo ainda tem uma enorme trajetória na busca para romper com os empecilhos da ordem societária, por isso, mesmo diante de tantos progressos, a luta para a emancipação das mulheres deve permanecer constante. Por consequência da conjuntura, houve transformações na relação entre feminismos e Estado. O movimento estava se legitimando e se institucionalizando e, com as pressões dirigidas aos diferentes níveis de governo, ocorreu a implementação de políticas públicas 


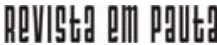

\} NOTAS SOBRE O FEMINISMO - LIMA, B. G. S.; CRUZ, M. H. S. \}

DOI: $10.12957 /$ rep.2021.56077

especificamente para as mulheres, algo que será discutido posteriormente no estudo presente. Dessa forma, é relevante analisar como se deu essa relação a partir da perspectiva de gênero, apreendendo a contribuição das medidas iniciativas do Estado, ainda que de forma embrionária, para transformação do padrão atual, arraigado profundamente na sociedade brasileira.

\section{Estudos feministas e estudos de gênero: compreendendo a discussão}

A emergência de romper com a estrutura patriarcal é o ponto de partida para o movimento feminista. É por meio da visão crítica da sociedade, ao visar ao rompimento com a exploração e a opressão sexista, bem como pela reivindicação de igualdade de direitos e oportunidades para a mudança social, que o movimento traz contribuições fundamentais para aprofundar o pensamento feminista através de discussões e estudos.

Inicialmente, o movimento se manifestou com discussões relacionadas ao feminismo envolvendo a categoria "mulher" nos estudos acadêmicos. Foram discutidas pautas relacionadas às condições de inferioridade e discriminação das mulheres na sociedade, na busca de denunciar as desigualdades. Acadêmicas feministas tiveram um papel de imensa relevância para colocar em destaque os estudos de gênero em ambientes intelectuais, com debates que estavam voltados para a situação política, social e econômica das mulheres. Os estudos feministas estavam baseados em "dois patamares epistemológicos", em que o primeiro está relacionado ao estudo das mulheres, analisadas como classe homogênea e consideradas perpassando uma narrativa de natureza humana universal. A segunda dimensão trata dos estudos de gênero, havendo uma transformação no objeto de estudo, analisando-o através de um caráter epistemológico.

Os estudos de gênero inseridos no quadro científico foram de fundamental importância, visto que era preciso que houvesse o reconhecimento de dimensões relacionadas ao transversal, interdisciplinar e interdependente das dinâmicas sociais. Tais estudos foram ressaltados através da luta das mulheres, configurando-se como um processo gradual e extenso, porém, conseguindo aos poucos sua inserção nos espaços acadêmicos e na produção científica. Em relação a isso, Dutra e Bandeira (2015, p. 2 - Grifos no original) enfatizam que

Um arcabouço teórico em cuja gênese pode identificar a pertinência do debate interdisciplinar, dos estudos comparados, das lutas de classe, da divisão social e sexual do trabalho, da segregação ocupacional, da interseccionalidade com as questões étnicas e raciais, da discriminação racial e retributiva, da violência sexual, das esferas do trabalho produtivo/reprodutivo; enfim, da construção cultural binária do mundo em termos do dever ser feminino ou masculino. 


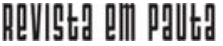

\} NOTAS SOBRE O FEMINISMO - LIMA, B. G. S.; CRUZ, M. H. S. \}

DOI: $10.12957 /$ rep.2021.56077

Evidencia-se que o feminismo se encontra cada vez mais multifacetado, diante das diversas perspectivas que são englobadas em determinadas vertentes. E, como afirma Pimentel (2017), expressa-se por um denominador comum, o qual seria a reprodução de opressão das mulheres através das relações de gênero. Dessa forma, colocam-se em evidência os estudos de gênero no ambiente acadêmico.

As relações de gênero são consideradas antagônicas e assimétricas, sendo uma pauta que se fortaleceu depois de muita luta do movimento feminista. Foi na década de 1970 que pesquisadoras envolvidas no movimento buscaram a inclusão de estudos de gênero e participação no processo de desenvolvimento de programas de pesquisas sobre temáticas e questões com valor científico, com o objetivo de denunciar a opressão que as muIheres sofriam e, a partir disso, refletir sobre a realidade delas na sociedade (DUTRA; BANDEIRA, 2015).

Os estudos de gênero se colocam em uma conjuntura com as mais diversas correntes do feminismo, mas têm como pauta comum a defesa dos direitos das mulheres, colocando em perspectiva a ótica do patriarcado. Dutra e Bandeira (2015, p. 5) discorrem que "[...] a diversidade atual no âmbito do que se convenciona chamar Estudos de Gênero, dialoga com as diferenças e pluralidades das lutas existentes no cerne dos movimentos sociais".

No Brasil, os estudos de gênero ganharam relevância no período da década da mulher. Segundo Tabak (1985, p. 1), esse acontecimento "[...] reuniu na cidade do México milhares e milhares de pessoas para celebrar o Ano Internacional da Mulher, proclamado pela Organização das Nações Unidas (ONU), em 1975". Mesmo sendo uma época marcada pela ditadura, grupos feministas permaneceram formados e houve publicações sobre desigualdades de gênero. Foi durante os anos 1980 que foram criados núcleos e grupos de trabalho sobre temáticas relacionadas ao gênero em articulação com as ciências sociais e humanas (CARVALHO et al., 2015).

Houve diversos questionamentos acerca dos estudos de gênero, portanto, foi um processo conturbado. Depois do surgimento de estudos voltados para a mulher, as análises e os estudos passaram a buscar compreender as relações entre os sexos e também as relações de poder e subordinação, sem se limitar à situação em que a mulher se encontra. Nos anos 1980, a discussão sobre as experiências das mulheres se fortalece, quando a mulher deixa de ser o sujeito universal, colocando as experiências das mulheres - no plural - em destaque. É importante destacar que, como afirmam Dutra e Bandeira (2015, p. 7),

[...] não se trata aqui de reduzir um processo de lutas sociais e produção de conhecimento acadêmico a uma simples recuperação sincrônica de fatos e ideias. Todas as correntes de pensamento atualmente ancoradas sob a denominação Estudos de Gênero, passam por constantes transformações e revisões críticas, por instâncias de 
disputas políticas e epistêmicas, assim como também de convergências.

Colocar a perspectiva de gênero em um patamar diferente no ambiente acadêmico tem o objetivo de transformar eticamente as discussões relacionadas à equidade e à diversidade. Essa inclusão visa a uma perspectiva crítica por outro olhar, desconstruindo o arcabouço científico que é considerado positivista e tradicional, impactando de forma relevante nas instituições e na sociedade no geral (CARVALHO et al.,2015).

Mesmo com a relevância das políticas voltadas para a questão de gênero, o número de mulheres envolvidas na produção de conhecimento ainda é escasso no mundo inteiro. Os obstáculos ainda persistem e eles se dão pela influência e domínio da cultura masculina em ambiência acadêmica. Além disso, a grande quantidade de estudos de gênero que vem sendo trazida para espaços intelectuais dificilmente é reconhecida, pois essa temática é entendida como exclusivamente da mulher. Mas, como afirma Carvalho et al. (2015, p. 4), está relacionada como "[...] as relações entre os sexos se reproduzem, institucionalizam e produzem discriminações, portanto remete a relações de poder e subordinação, sem se limitar a assinalar a posição ocupada pela mulher".

Mesmo diante dessa situação, os núcleos de estudo de gênero continuam a buscar e discutir as pautas para desconstrução de um conhecimento acadêmico tradicional, uma vez que é necessário que a perspectiva de gênero esteja englobada em assuntos científicos em todas as áreas de conhecimento, com o objetivo de garantir a equidade, seja no espaço acadêmico ou fora dele, e a transformação das relações sociais.

\section{A categoria "gênero"}

Existem duas perspectivas acerca do termo "gênero" dentro do movimento feminista. Uma relaciona-se a estar contrário ao "sexo", em que ambos os termos são apontados como opostos. Ao contrário do que é biologicamente dado e considerando o que é socialmente construído, visa ao comportamento e à personalidade dos indivíduos, e não ao corpo. A outra perspectiva é referente à distinção entre masculino e feminino, relacionada a qualquer construção social, levando em consideração não só o comportamento e a personalidade, mas também a forma como o corpo é visto. Dessa maneira, o "sexo" está intrinsicamente ligado à categoria "gênero" (NICHOLSON, 2000).

Nos anos 1960, o conceito de "gênero" buscava distinguir masculino e feminino a partir de "determinações biológicas", mas as mulheres feministas dessa fase ressignificaram o termo incrementando as diferenças entre homens e mulheres relacionadas ao social, e não somente ao biológico. 
Segundo esta visão, as mulheres e os homens eram definidos em termos recíprocos e não se poderia compreender qualquer um dos sexos por meio de um estudo inteiramente separado. Assim, Natalie Davis afirmava, em 1975: 'Penso que deveríamos nos interessar pela história tanto dos homens como das mulheres, e que não deveríamos tratar somente do sexo sujeitado, assim como um historiador de classe não pode fixar seu olhar apenas sobre os camponeses. Nosso objetivo é compreender a importância dos sexos, isto é, dos grupos de gênero no passado histórico. Nosso objetivo é descobrir o leque de papéis e de simbolismos sexuais nas diferentes sociedades e períodos, é encontrar qual era o seu sentido e como eles funcionavam para manter a ordem social ou para mudá-la'. (SCOTT, 1995, p. 72).

Segundo Nicholson (2000, n. p.), "[...] 'gênero', naquela época, não era visto pela maioria como substituto para 'sexo', mas como meio de minar as pretensões de abrangência do 'sexo'". Destarte, "gênero" passou a ser um termo que complementa o que é "sexo", sem precisar substituí-lo, sendo um conceito necessário para que seu significado seja mais abrangente e elaborado. O segundo panorama é que se sobressai no feminismo, mas ainda existem resquícios da primeira visão, em que o "sexo" é exterior à cultura e à história, diferenciando masculino e feminino.

A partir da segunda perspectiva, o termo "gênero" surgiu inicialmente com as feministas americanas, que buscavam rejeitar a compreensão do conceito por determinismo biológico, mas procuravam dar importância aos fundamentos sociais de distinções baseadas no sexo. A produção de conhecimentos sobre a mulher estava cada vez mais limitada e o conceito de gênero foi essencial para entender as relações sociais e a definição de homem e mulher, pois somente dessa maneira é possível compreender os sexos (SCOTT, 1995).

Outro aspecto é que o conceito de "gênero" está relacionado não só às mulheres, mas também aos homens, em que cada um implica nos estudos do outro. Essa perspectiva busca compreender as relações sociais entre os sexos, considerando a estrutura da sociedade, as construções culturais e a identidade subjetiva de ambos os sexos.

Então, as relações de gênero objetivam apreender o homem e a mulher como seres sociais, e não como seres biológicos, diferenciando-os para conhecer e definir as características que implicam a identidade do feminino e do masculino. Gênero está relacionado às relações sociais, à estrutura da sociedade e às práticas cotidianas a que os indivíduos estão submetidos. Com discorre Souza (2013, p. 2), "[...] podemos dizer que gênero é relacional, sócio-histórica, pois não nascemos homens ou mulheres, mas aprendemos ao longo da nossa existência, o ser homem e o ser mulher, assim nos tornamos a partir de nossas experiências".

A partir dessa dimensão, entende-se que a construção de determinado sujeito não se deve apenas pela sua consciência como indivíduo, mas são as relações sociais que permitem a sua construção como ser social. 
Os comportamentos e os padrões impostos pela sociedade, que existem independentemente da vontade das pessoas, são fenômenos que influenciam fortemente.

A sociedade em seu contexto histórico constantemente impõe uma série de responsabilidades alheias e contra a vontade das pessoas, que incorporam modelos e comportamentos mutuamente excludentes, no sentido de que um destes se sobrepõe ao outro, adotando arquétipos, estereótipos os quais devem ser seguidos rigidamente em função do sexismo, que implica em divisão de tarefas, e consequentemente engessam masculino e feminino, padronizando-os: o primeiro na esfera da vida pública e o segundo na vida privada. (SOUZA, 2013, p. 2).

Estudar gênero é fundamental para compreender como se dão as diversas maneiras de desigualdade entre mulheres e homens, bem como para entender como surgiram e como acontecem as relações de opressão e submissão, fenômenos que são naturalizados e estão enraizados na sociedade. A compreensão da sua importância e contribuição para a emancipação das mulheres deve ser destacada, já que é através da troca de saberes relacionados a essa temática que se fortalecem as ideias e os ideais importantes para o enriquecimento de conhecimento histórico, crítico e teórico e para a problematização de condições de desigualdade entre gêneros em uma sociedade patriarcal e capitalista, em um cenário de reflexão crítica e de reivindicações.

\section{Feminismo, gênero e políticas públicas no Brasil}

Numa sociedade que é regida pelo capitalismo - sistema políticoeconômico que tem a desigualdade e a exclusão social como alguns de seus fundamentos -, faz-se necessária a implementação de políticas públicas para dar respostas às problemáticas sociais existentes. Elas se deram por meio da pressão e da mobilização da classe trabalhadora através dos movimentos sociais; com isso, o Estado passou a ser o órgão responsável para a aplicação dessas políticas, desempenhando o papel de mediador entre as exigências da ordem capitalista e as demandas da classe trabalhadora (ROCHA, 2016).

Para compreender as políticas públicas relacionadas à perspectiva de gênero, é preciso analisar como o Estado passa a contribuir para transformar o padrão que enraizado na sociedade brasileira. Foi a partir dos anos 1970 que se iniciou o processo de reforma da sociedade buscando a redemocratização, já que nos anos anteriores o país passava por uma ditadura militar. A população brasileira teve fundamental importância no desenvolver desse processo, principalmente ao reivindicar a garantia de seus direitos através das políticas públicas (FARAH, 2004). 
Nos anos 1980, diante de uma sociedade que aderiu aos preceitos do neoliberalismo, sendo marcada fortemente por complexos fenômenos, como a pobreza e o desemprego, as mulheres vislumbraram a necessidade de colocar em evidência a perspectiva feminista, já que, além de esses fenômenos atingirem diretamente as mulheres, existe também a discriminação de gênero, sendo mais um desafio a ser enfrentado. Buscando mudanças relacionadas às condições das mulheres na sociedade, o feminismo pretende romper com as diversas formas de desigualdade intrínsecas às relações sociais.

A mobilização da população feminina no processo de redemocratização foi imprescindível para que elas se constituíssem como sujeito político. Além disso, o movimento também passou a inserir discussões visando compreender o patriarcado e as relações de poder existentes na sociedade. Daí surge a necessidade de o movimento estar diretamente envolvido com as políticas sociais.

Então, a princípio, essa pauta foi destacada por teóricas feministas por meio dos fóruns internacionais que aconteciam nessa época, tendo demandas contempladas e registradas na Convenção sobre a eliminação de todas as formas de discriminação contra a mulher (Cedaw), que foi "[...] adotada em 1979 pela Assembleia Geral da ONU, [em que] definiu o que constitui discriminação contra as mulheres e apresentou uma agenda de atividades nacionais visando eliminar essa discriminação" (PRÁ; EPPING, 2012, p. 39).

O Brasil tem participado e levado suas demandas para os mais diversos espaços significativos de caráter internacional. Com isso, o movimento feminista se inclui dentro desse espaço conquistado, com a intenção de dar o reconhecimento necessário às demandas, buscando maneiras de elas serem atendidas e consideradas. Desse modo, são estudados e discutidos instrumentos com o objetivo de proteger e expandir os direitos das mulheres através de acordos, protocolos, tratados e planos formulados no interior desses espaços políticos. Essas conquistas se deram por meio das mobilizações e das lutas, que visavam a possibilidade de dialogar e decidir com as instâncias sociais e governamentais as políticas públicas para garantir e ampliar a equidade de gênero e os direitos das mulheres, sejam eles sociais, políticos, reprodutivos, culturais ou sexuais (PRÁ; EPPING, 2012).

Ao ter êxito em ocupar os espaços políticos, a perspectiva de gênero foi considerada nas mais diversas conferências e encontros que aconteciam em todo o mundo. Alguns exemplos desses espaços são a ECO92 (1992), sobre Meio Ambiente; a Conferência Mundial sobre Direitos Humanos, em 1993; a Conferência sobre População e Desenvolvimento, em 1994; a Cúpula Mundial sobre Desenvolvimento Social, em 1995; a Conferência Mundial sobre a Mulher, em 1995; e o Fórum Social Mundial, de 2001 a 2003 (FARAH, 2004). 


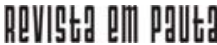

\} NOTAS SOBRE O FEMINISMO - LIMA, B. G. S.; CRUZ, M. H. S. \}

DOI: $10.12957 /$ rep. 2021.56077

Além dessas conferências, a participação das mulheres foi fundamental no processo de formulação de políticas públicas com recortes de gênero, como por exemplo no desenvolvimento do ciclo social da ONU e de documentos ratificados pelo Brasil, como o Protocolo facultativo à convenção sobre a eliminação de todas as formas de discriminação contra a mulher (Cedaw - 1979) e o Plano de ação da conferência de Beijing (1995).

Na década de 1980, o Brasil foi marcado fortemente pelos efeitos das mobilizações por parte das mulheres, pois as primeiras políticas públicas com recorte de gênero começaram a ser implantadas. De início, foram fundados em São Paulo dois órgãos muito importantes: em 1983, o Conselho Estadual da Condição Feminina e, em 1985, a primeira Delegacia de Polícia de Defesa da Mulher. Esse foi o ponto de partida para difundir tais instituições pelo país inteiro. Em 1985, originou-se o Conselho Nacional dos Direitos da Mulher, órgão do Ministério da Justiça e, em 1983, instituiu-se o Programa de Assistência Integral à Saúde da Mulher (Paism), mediante a mobilização de mulheres (FARAH, 2004).

Dessa forma, é perceptível que a luta das mulheres para inserirem as questões de gênero nas políticas públicas foi - e é - de grande importância na discussão da realidade política e social, porque é através desses espaços de participação e de reivindicação que os direitos humanos das mulheres são colocados em debate de maneira democrática, objetivando mudanças necessárias para a superação das diversas formas de discriminação e de relações de poder que persistem na sociedade.

\section{Considerações finais}

Ao considerar todo o percurso realizado pelo movimento feminista, é perceptível a intensa luta para transformar a realidade a que as muIheres são submetidas, num cenário marcado por condições de opressão. Mudar toda a estrutura vigente sobre as ideias de gênero é imprescindível para o movimento a fim de que sejam construídas as bases que levam à igualdade de direitos.

É importante destacar a relevância da união e da intervenção das feministas brasileiras dentro das mais diversas conferências e encontros mundiais, refletindo sobre a influência do movimento nos diferentes espaços políticos. Tendo o poder de reivindicar e decidir acerca dos próprios direitos, tanto na agenda pública internacional como também na nacional, acabam se confrontando com limites nas relações de poder diante de uma atuação de forte resistência para tais obstáculos.

Mesmo com toda a mobilização e com o avanço em determinadas pautas, as mulheres ainda não têm todas as suas reivindicações consideradas e não ocupam a maioria dos espaços existentes. São inúmeros os desafios no marco das relações de poder que se manifestam na realidade, mas os 


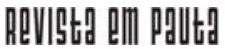

\} NOTAS SOBRE O FEMINISMO - LIMA, B. G. S.; CRUZ, M. H. S. \}

DOI: $10.12957 /$ rep.2021.56077

questionamentos trazidos para serem discutidos no movimento são de grande importância para explorar reflexões, oferecer novas perspectivas e redefinir termos e conteúdo, colocando as mulheres em condição de participantes ativas para pressionar o Estado e a sociedade, buscando estratégias que possibilitem as reivindicações das políticas feministas, de igualdade política e social, consideradas e cumpridas nas políticas públicas. 


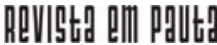

\} NOTAS SOBRE O FEMINISMO - LIMA, B. G. S.; CRUZ, M. H. S. \}

DOI: $10.12957 /$ rep. 2021.56077

\section{Referências}

CARVALHO, M. E. P. et al. Origens e desafios dos núcleos de estudos de gênero na educação superior no Norte e Nordeste do Brasil. In: REUNIÃO NACIONAL DA ANPED, 37, Florianópolis, out. 2015. Disponível em: http:/ /37 reuniao.anped.org.br/wp-content/uploads/2015/02/Trabalho-GT233761.pdf. Acesso em: 6 jul. 2019.

DUARTE, C. L. Feminismo e literatura no Brasil. Estudos Avançados, v. 17, n. 49, 2003. Disponível em: http://www.scielo.br/scielo.php?script=sci_ arttext\&pid=S0103-40142003000300010. Acesso em: 5 jul. 2019.

DUTRA, D.; BANDEIRA, L. M. Estudos de gênero na América Latina: dinâmicas epistêmicas e emancipações plurais. Revista de Estudos e Pesquisas sobre as Américas, v. 9, n. 2, 2015. Disponível em: http://periodicos.unb.br/ index.php/repam/article/download/17267/12644. Acesso em: 6 jul. 2019.

FARAH, M. F. Gênero e políticas públicas. Estudos Feministas, Florianópolis, v. 12, n. 1, jan./abr. 2004. Disponível em: https://periodicos.ufsc.br/index. php/ref/article/view/S0104-026X2004000100004. Acesso em: 13 jul. 2019.

FERREIRA, V. O Feminismo na pós-modernidade. Revista Crítica de Ciências Sociais, Coimbra, n. 24, mar. 1988. Disponível em: https://www.ces.uc.pt/ publicacoes/rccs/artigos/24/_Virginia \%20Ferreira \%20-\%200\%20Fe minismo\%20na\%20Pos-Modernidade.pdf. Acesso em: 6 jun. 2019.

$\mathrm{NICHOLSON,} \mathrm{L.} \mathrm{Interpretando} \mathrm{gênero.} \mathrm{Estudos} \mathrm{Feministas,} \mathrm{Florianópolis,}$ v. 8, n. 2, 2000. Disponível em: https://periodicos.ufsc.br/index.php/ref/ article/view/11917/11167. Acesso em: 11 jul. 2019.

PIMENTEL, E. Prisões femininas: por uma perspectiva feminista e interseccional. In: STEVENS, C. et al. (Org.). Mulheres e violências: interseccionalidade. Brasília: Technopolitik, 2017. Disponível em: https://www. geledes.org.br/wp-content/uploads/2017/03/Mulheres-e-viol\%C3\%AAnciasinterseccionalidades.pdf. Acesso em: 11 jul. 2019.

PRÁ, J. R.; EPPING, L. Cidadania e feminismo no reconhecimento dos direitos humanos das mulheres. Estudos Feministas, Florianópolis, v. 20, n. 1, jan./abr. 2012. Disponível em: https://periodicos.ufsc.br/index.php/ref/ article/view/S0104-026X2012000100003. Acesso em: 13 jul. 2019.

ROCHA, L. M. L. N. Feminismo, gênero e políticas públicas: desafios para fortalecer a luta pela emancipação. Revista Políticas Públicas, São Luís, nov. 2016. Disponível em: http://www.periodicoseletronicos.ufma.br/index. php/rppublica/article/view/5982/3616. Acesso em: 6 jul. 2019.

SARDENBERG, C; COSTA, A. A. Feminismos no Brasil: enunciando e canalizando demandas das mulheres em sua diversidade. Labrys, jan./jun. 2012. 


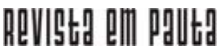

\} NOTAS SOBRE O FEMINISMO - LIMA, B. G. S.; CRUZ, M. H. S. \}

DOI: $10.12957 /$ rep.2021.56077

Disponível em: https://www.labrys.net.br/labrys20/brasil/cecilia.htm. Acesso em: 5 jul. 2019.

SCOTT, J. W. Gênero: uma categoria útil de análise histórica. Educação e Realidade, v. 20, n. 2, jul./dez. 1995. Disponível em: https://seer.ufrgs.br/ educacaoerealidade/article/view/71721. Acesso em: 11 jul. 2019.

SOUZA, F. M. L. Algumas reflexões acerca de gênero: uma perspectiva marxista. 2013. Disponível em: https://semanaecopol.files.wordpress.com/ 2013/10/gt-2-fc3a1 rida-maressa-loureiro-e-souza-algumas-reflexc3b5esacerca-de-gc3aanero.pdf. Acesso em: 11 jul. 2019.

TABAK, F. A década da mulher como forma de participação e pressão política - Avaliação e balanço. In: REUNIÃO ANUAL DA ANPOCS, GT MULHER E POLÍTICA, 9, 1985. Disponível em: http://anpocs.org/index.php/ encontros/papers/9-encontro-anual-da-anpocs/gt-10/gt21-6/6147-fanny tabak-decada/file. Acesso em: 12 jul. 2019.

DOI: $10.12957 /$ rep.2021.56077

Recebido em 09 de março de 2020.

Aprovado para publicação em 27 de setembro de 2020.

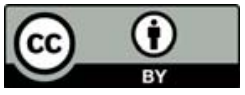

A Revista Em Pauta: Teoria Social e Realidade Contemporânea está licenciada com uma Licença Creative Commons Atribuição 4.0 Internacional. 